\title{
Estimating total body heat dissipation in air and water from skin surface heat flux telemetry in Weddell seals
}

\author{
Allyson G. Hindle ${ }^{1,2^{*}}$, Markus Horning ${ }^{2,3}$ and Jo-Ann E. Mellish²,4
}

\begin{abstract}
Background: Accurate estimates of thermoregulatory costs in air and water are necessary to predict the impacts of changing habitats to individuals and populations of ice-obligate seals. Investigations that would provide such estimates of thermoregulatory physiology over natural activities in free-ranging marine mammals have been limited. This study describes a biotelemetry method for measuring skin surface heat flux in free-ranging Weddell seals. These data are then applied to estimations of thermoregulatory heat dissipation from multiple point measurements.

Results: Data loggers collecting skin surface heat flux telemetry at four body locations (head, neck, axilla and flank) from 40 free-ranging Weddell seals were deployed and recovered over periods of 1-13 days in Erebus Bay, Antarctica. We derive equations for estimating total body heat dissipation from these point measurements and demonstrate the subsequent calculation of heat dissipated from obligate thermoregulatory costs. Heat lost to air or water was described by heat flux sensor data extrapolated across the whole-body surface, as informed by skin surface infrared thermal patterns. Heat lost directly to the ice surface during haul-out was best described by physical features of the seal, rather than environmental variables. Heat flux inputs from the four sensors could be reduced to two principal components, and corresponding regressions indicated that the axilla and flank sensors were most correlated with total body heat dissipation in air and water. Variability in head sensor heat flux was least described by the two principal components.
\end{abstract}

Conclusions: This method can be used to estimate total body heat dissipation during daily activities in marine mammals, and under steady-state conditions, it can be used to identify obligate thermoregulatory heat costs. Ultimately this type of data will provide relevant empirical information for parameterizing models of thermoregulatory energetics in ice-obligate seals, which may improve our ability to predict outcomes of altered ice conditions at high latitudes.

Keywords: Thermoregulation, Heat loss, Ice seal, Pinniped

\section{Background}

One of the most predictable outcomes of current polar ice dynamics is a dramatic change in extent and persistence of Arctic summer ice [1, 2]. By comparison, regional ice dynamics are highly variable in the Southern Ocean [3], ranging from thinning and loss $[4,5]$, to increased regional sea ice extent and persistence due to increased fragmentation of ice shelves $[1,2,6]$. Any changes in sea ice extent have the potential to impact polar pinnipeds

*Correspondence: ahindle@mgh.harvard.edu

2 Alaska SeaLife Center, Seward, AK 99664, USA

Full list of author information is available at the end of the article (seals and sea lions), which rely on this habitat as a platform for resting, molting, and pup rearing. Further, these species stand to incur thermoregulatory costs associated with significant shifts in ice dynamics due to a forced change in the amount of time spent in air versus water. Accurate predictions of individual and population level outcomes of habitat change rely on accurate knowledge of baseline physiology and its plasticity. Several studies have investigated thermoregulatory physiology of polar pinnipeds by modeling, from single sampling events, or under specific controlled conditions [7-17]. In contrast, biologging technologies are only beginning to be applied 
to study thermoregulation in free-living marine mammals at any latitude [18-20].

Pinnipeds, particularly phocid seals, reduce heat transfer to the environment by reducing skin temperature, and insulating the skin surface from the body core with a thick layer of subcutaneous blubber. However, the rate of heat loss by aquatic homeotherms is $1.5-4.5 \times$ greater in water versus air, as water has $25 \times$ greater thermal conductivity [21]. Components of heat loss also fundamentally differ between air and water. In air, heat transfer can occur by conduction, convection, radiation and evaporation, while only free and forced convection are relevant during diving.

A basic principal of thermoregulation is that all energetic processes liberate heat. Metabolic heat generated via basal metabolism, locomotion and digestion (i.e., the heat increment of feeding, HIF) as examples, may be applied to the maintenance of homeothermy. The degree to which locomotory heat production and HIF can be captured and will substitute for active thermogenesis appears to be species and environment specific [22]. Studies in semi-aquatic and marine homeotherms that have directly tested a substitutive effect of HIF on thermoregulatory heat production have yielded mixed results [23-25]. Increased postprandial metabolic rate has also been described in sea otters [26], fur seals [27] and phocid seals $[8,28-30]$, but to what degree HIF may defray thermoregulatory costs in the post-dive surface period is not clear. Heat derived from locomotion may also offset obligate heat production at temperatures below the thermoneutral zone, including in diving endotherms (reviewed by [31]). Ultimately, the heat required to maintain stable body temperature that is not captured from HIF or locomotion must be met by facultative thermogenesis. We can infer total metabolic heat production in a core homeotherm by measuring total heat loss. By placing this information in the context of behavior (e.g., swim speed) and physiological state (e.g., fed/fasted), we can estimate the energetic (heat dissipation) costs of specific processes, including obligate thermoregulation.

Describing total metabolic energy production as the sum of basal metabolism (BM), cost of locomotion (CL), HIF, and thermoregulation (TR) is a valid short-term simplification for diving animals that excludes costs of anabolism, respiration and excretion [32]. From this, we infer a comparable relationship for metabolic heat loss under conditions of thermal homeostasis:

$$
\mathrm{TBHD}=H_{\mathrm{BM}}+H_{\mathrm{CL}}+\mathrm{HIF}+H_{\mathrm{TR}}
$$

where TBHD is total body heat dissipation, and $H$ denotes the heat dissipation from each metabolic process (BM, CL, HIF and TR).
We present a method for measuring heat loss using recoverable dataloggers over short-term deployments via skin surface heat flux (HF) in a free-swimming polar seal. We calculate TBHD in air and water from HF point measurements from species and individual-specific morphometric information. This method will provide relevant empirical data for parameterizing models of thermoregulatory energetics in ice-obligate seals, which may improve our ability to predict outcomes of altered ice conditions at high latitudes. We chose the Antarctic Weddell seal as a model in which to develop this technique due to accessibility for the multiple handling events needed for high-resolution logged data recovery relative to Arctic seals. Weddell seals are also an ideal species for the study of thermoregulation $[13,14]$ due to their wide natural intra-specific variation in body size and condition, particularly during the breeding season.

\section{Methods}

\section{Study animals and instrumentation}

All work was conducted under Marine Mammal Protection Act (\#15748) and Antarctic Conservation Act (\#2012-003) permits. We collected HF data from 40 freeranging Weddell seals during the austral spring (October-December 2011 and 2012) in McMurdo Sound, Antarctica $\left(77^{\circ} 53^{\prime} \mathrm{S} 166^{\circ} 40^{\prime} \mathrm{E}\right)$. We selected study animals from four life history categories to incorporate a range of intraspecific size and body condition: weaned pups ( $>35$ days, $n=10)$, juveniles $(1-2$ years old, $n=10)$, adult females that did not produce a pup (skip breeders, $n=11)$, and post-weaning adult females $(n=9)$. Seals were initially restrained by head bag and anesthetized [33] for health assessments and instrument attachment. Animals carried front and rear time-depth recorders placed on the dorsal midline (Mk10-custom, Wildlife Computers, Redmond WA), which each logged 3-dimensional acceleration and two channels of HF data. Combined, the data loggers allowed us to monitor skin surface HF and temperature at four body sites-head, neck, axilla and flank (Fig. 1; description of site selection below). HF sensors (25.4 mm diameter, Concept Engineering, Old Saybrook, CT), which also measured surface temperatures, were placed on the shaved skin surface of the seal. Sensors were affixed to the skin with a coating of thermally conductive adhesive paste (Omegatherm OTC201, Omega Engineering, Stamford CT) and secured for multi-day deployments with a thin cuff of PVC that protected the outer edge of the circular HF sensors and was superglued (Loctite 422 cyanoacrylate gel) to the animal's skin (Fig. 1, inset). The cables connecting the HF sensors to the data loggers were tacked to the fur with small neoprene strips. Body temperature and feeding signals were 


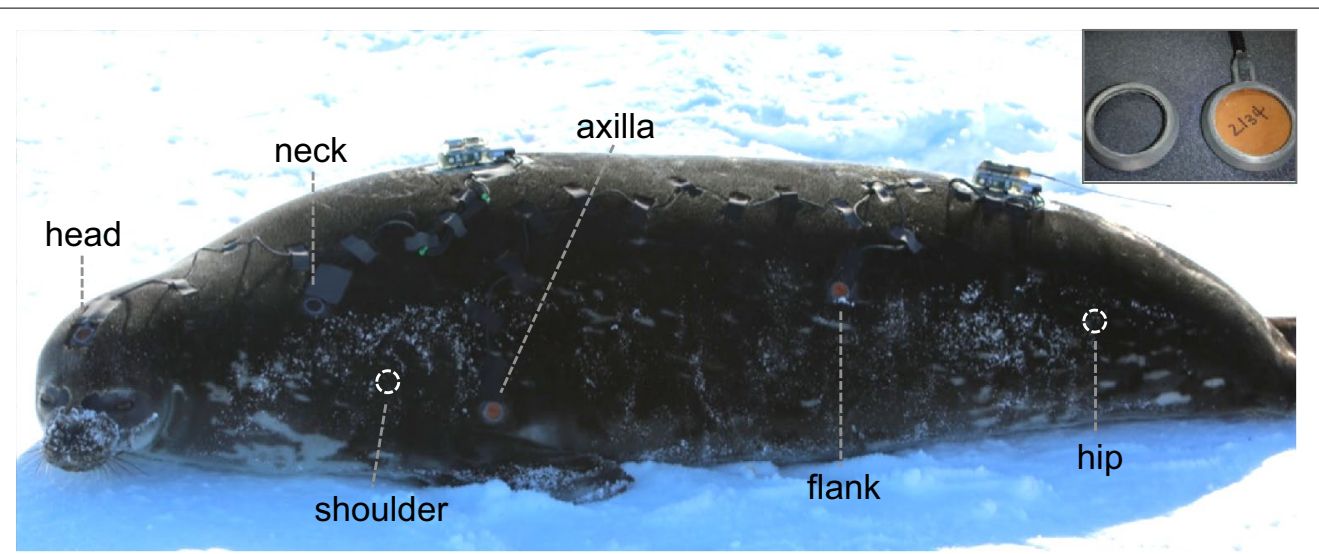

Fig. 1 Skin surface heat flux was measured at four sites in free-ranging Weddell seals. Sensors are shown at sites termed head, neck, axilla and flank. Initial trials were conducted with six sensors placements (also including shoulder and hip), whose locations are depicted by circles. Photo inset shows the heat flux sensor and protective PVC cuff that was attached to the skin (right, PVC cuff alone on left)

monitored from a stomach temperature pill inserted by gavage (STP, Wildlife Computers), which transmitted data to the front logger. Animals additionally carried both an ARGOS satellite and a VHF radio beacon to enable recapture and instrument recovery.

\section{Additional data collected}

Infrared thermograms (IRT) were collected to inform sensor placement and HF analyses. IRTs were collected from the lateral surfaces of our dry, instrumented animals prior to handling ( $n=34$ complete IRT and HF datasets, plus $n=3$ juveniles with no recovered HF data). An analysis of these data is presented elsewhere [13]. We also imaged recently emerged, wet seals (unknown adults, $n=14)$ as well as a drying time series $(n=7)$. Images were collected with either a FLIR P25 or P640 infrared camera (FLIR Systems, Danderyd, Sweden), with resolution of $320 \times 240$ and $640 \times 480$ pixels, respectively. Cameras were factory calibrated to an absolute accuracy of $\pm 2{ }^{\circ} \mathrm{C}$ and sensitivity of $<0.10^{\circ} \mathrm{C}$. Additional details of imaging equipment and conditions are outlined in Mellish et al. [13]. Wind speed, air temperature and humidity were recorded for each imaging event with a SPER Scientific Ltd Mini Environmental Quality Meter (Sper Scientific Ltd, Scottsdale, AZ, USA). Over the deployment periods, air temperature and wind speed were obtained in 10-min intervals from local weather stations (US Navy SPAWAR Systems Center Atlantic, Polar Programs IPT).

Morphometrics and blubber depths were collected as baseline body size and condition data. Sedated seals were weighed with a tripod and suspended scale $( \pm 0.5 \mathrm{~kg}$, San Diego Scale). Blubber depth was measured at 10 body locations by imaging ultrasound [13, 33, 34]. Body surface area and volume were collected for each individual by photogrammetry. Four simultaneous images were captured of each individual with Nikon D100 (2011 animals) or Olympus EPL-1 (2012) cameras, such that the animal's nose and a reference marker at the rear of the seal were visible in all images. The cameras were pre-calibrated in Photomodeler 3D modeling software (Eos Systems, Inc., USA). Reference markers were placed on the seal in several locations to scale and reference the images. Photo sets were imported into Photomodeler for referencing (using all available matched reference points in the image) and orientation (two $x$ and two $y$ coordinates per set) among the four photos. Wireframe models were created of each seal from the matched image sets. The resulting wireframe was exported to Rhino 3D modeling software (Robert McNeel \& Associates, USA), which was calculated the surface area and volume of the wireframe. In addition to whole-body surface area and volume, we determined the surface area of hauled-out seals in contact with the ice.

As a measure of underwater activity for use in HF modeling, we calculated overall dynamic body acceleration (ODBA) using the front accelerometer. We derived static acceleration for each dimension using 3-s smoothed data (per [35, 36]), and converted acceleration by $1 \mathrm{~g}=9.83 \mathrm{~m} / \mathrm{s}^{2}$.

\section{Data processing}

A schematic outlines data processing and analyses (Additional file 1). Downloaded data from the two time-depth recorders were synced by time stamp and depth trace using HexTool (Wildlife Computers) and Igor Pro (Wavemetrics). A signal spike due to satellite beacon transmission was removed from depth, HF and skin temperature channels with a 3-point median filter. Each dataset was 
visually examined to determine the point in each HF/ temperature channel that indicated the end of usable data (i.e., sensor or cable damage). HF data were further filtered to remove values $>0.3 \mathrm{mV}$ in water; $\Delta \mathrm{HF}$ in water $<-15.0 \mathrm{mV} / \mathrm{s}$ or $>5.0 \mathrm{mV} / \mathrm{s}$ ), which represented the high and low ends of the expected data range (-HF indicates heat loss to the environment). Skin temperature data were filtered to remove data outside the maximum values and rates of change that were reasonable for the study system and were observed during activities of known high variability (e.g., entering/exiting water). Temperature data points were removed after 3-point median filter if $<-40{ }^{\circ} \mathrm{C}$; $<-2{ }^{\circ} \mathrm{C}$ in water; $>15.0{ }^{\circ} \mathrm{C}$ for head sensor in water; $>5.0^{\circ} \mathrm{C}$ for all other sensors in water; $\Delta$ temperature $<-2.0^{\circ} / \mathrm{s}$ or $>0.3^{\circ} / \mathrm{s}$. Filtered data for each sensor were subsequently converted from $\mathrm{mV}$ into $\mathrm{W} / \mathrm{m}^{2}$ using calibrations for each sensor provided by the manufacturer following methods recommended by the American Society for Testing Materials. Converted data were multiplied by a uniform correction factor ("1.25) to account for thermal resistance resulting from the insulating properties of the sensor and attachment itself. This correction factor was experimentally determined as described in Willis and Horning [20]. In brief, a test rig was constructed to measure heat transfer between adjacent, insulated compartments of recirculating water regulated to specific temperatures. Heat transfer across a bare sensor (expected values) was compared to transfer across a second sensor fitted with an additional HF disc and attachment (observed values). Five replicate measurements each were conducted at temperature gradients stepped from 0 to $20{ }^{\circ} \mathrm{C}$ in $2^{\circ}$ increments. Observed values were regressed against predicted and the correction factor calculated as the inverse regression slope.

\section{Data analyses}

HF sensor sites were selected from a suite of wet and dry animal images, incorporating sites that were stable or variable across a range of temperatures. Thermal imaging software (FLIR Researcher 2.8) was used to generate a temperature profile histogram for regions of interest. We applied principal components analysis with a varimax orthogonal rotation [37] to determine the number of independent variables needed to describe variance among measurements from the four HF sensor sites. Relationships between IRT data and HF among sensor sites, between states (wet versus dry), and among sampled groups were evaluated with ANOVA and linear mixed effects (LME) models with individual animal as a random factor, and with pairwise comparisons generated from Tukey's post hoc tests.

To extrapolate four point HF measurements into a whole-body measurement of heat loss, IRT surface temperature patterns in wet and dry seals were used to estimate the proportion of body surface best explained by each HF sensor. Specifically, we measured the surface area of body regions contiguous with each sensor that shared the same range of IRT temperature as the focal measurements at that sensor site, using Image (version 1.48a, National Institutes of Health, USA). For TBHD determination, HF from each sensor was applied over its corresponding surface area, with the remaining noncontiguous body regions represented by average HF from neck and flank.

Associations between heat lost to the ice substrate and animal (mass, average blubber depth, surface area, volume, surface area: mass and surface area: volume ratios) or environmental variables (air temperature, wind speed) were analyzed with LME models. Best-fit LME models were determined by AIC model selection methods. Intercepts of TBHD with activity in water were determined by quantile regression [38]. All statistical analyses were conducted in R version 3.0.2 [39]. Negative HF values indicate heat lost from animal to the environment. Data are presented mean \pm SD unless otherwise noted.

\section{Results \\ Dataset}

A total of 131 days of data with all four sensors functioning was retrieved from our 40 deployments (ranging from 1 to 13 days). In two individuals, one data logger failed, returning only two HF sensor records over the entire deployment. For the remaining 38 seals we recovered an average of $82.6 \mathrm{~h}$ of four-sensor data (range: 6-307 h). Seal mass ranged 5.7-fold (90-520 kg) and surface area to volume ratio varied $1.9 \times$. Body temperature measured by STP was $37.3 \pm 0.4{ }^{\circ} \mathrm{C}$ (grand mean) in hauled-out, postabsorptive Weddell seals.

\section{Heat flux site selection}

HF sensors were placed on the head at midline, and left side of the body at sites we termed neck, axilla and flank (Fig. 1). These sites were identified as warm/cool or stable/variable across IRT images of dry resting and wet, recently emerged seals. These criteria were intended to reflect the range of thermal patterns on the body surface of Weddell seals. Initial deployments with six sensors ( $n=4$ seals; Fig. 1), included the shoulder and hip; however, HF at these two sites did not fit the criteria of warm/ cool and stable/variable.

We compared focal IRT temperatures at the four sensor sites, and normalized values as difference relative to average surface temperature. For dry seals, both absolute and differential temperatures varied among sensor sites $(p=0.03$; Fig. 2$)$. Neck and head were universally the coldest and warmest locations, respectively (head versus neck $p=0.02$ ). This trend was also apparent in wet 


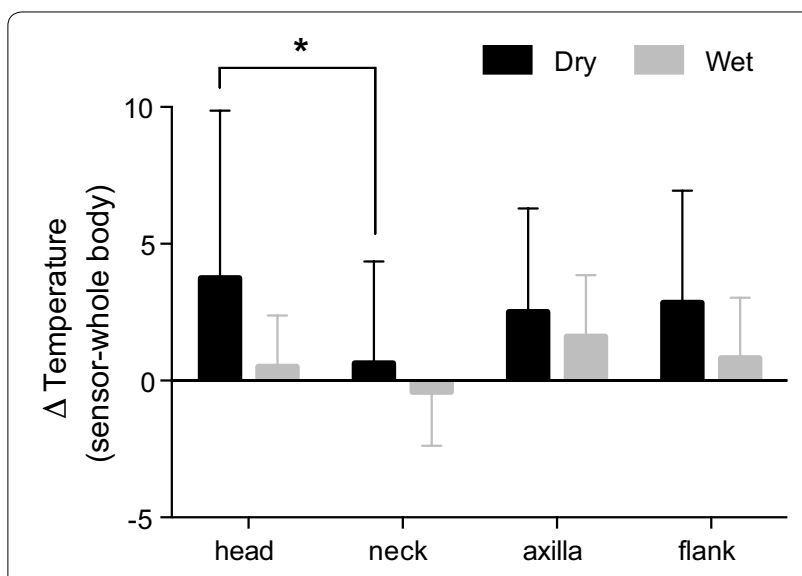

Fig. 2 Temperature patterns across four sites by infrared imaging. Infrared thermograms (lateral images) were used to determine focal temperature at each proposed sensor location as well as average surface temperature. The temperature difference between sensor site and whole-body average is presented in dry resting $(n=37)$ and wet, recently emerged $(n=14)$ seals

animals but did not meet significance ( $p=0.07$; Fig. 2). Consistent with IRT data, skin temperatures recorded by HF sensors over the free-ranging period were also generally highest at the head site and lowest at neck (Fig. 3a, b). Heat loss to the environment was highest from head in both air and water (Fig. 3c, d). Underwater, mean HF was more than doubled at the head site $\left(-204 \pm 95.4 \mathrm{~W} / \mathrm{m}^{2}\right)$ compared to all other sites (neck: $-82.3 \pm 46.2 \mathrm{~W} / \mathrm{m}^{2}$, axilla: $-91.5 \pm 86.8 \mathrm{~W} / \mathrm{m}^{2}$, flank: $-87.6 \pm 36.6 \mathrm{~W} / \mathrm{m}^{2}$ ). The axilla site was generally warmer than the flank site, and both displayed high HF variability, most obviously during haul-out (Fig. 3d).

\section{Calculating total body heat dissipation}

The surface area corresponding to the axilla temperature signature was $1.4 \times$ larger in recently emerged, wet seals (Tukey $p=0.01$; Fig. 4 ), but head, neck and flank did not differ between air and water $(p>0.05)$. The flank region was significantly larger in juveniles compared to all other groups (LME $\left.F_{12,165}=5.3, p<0.0001\right)$. To account for this, we applied group-specific values to this region (pup $=38.9 \%$, juvenile $=30.6 \%$, non-reproductive female $=41.9 \%$, post-weaning female $=38.7 \%$ of visible surface area) when extrapolating HF point measurements into TBHD. The region associated with head was $6.0 \%$ of the lateral surface area, while neck was $10.7 \%$. We applied the axilla value over $16.8 \%$ of seal surface area to calculate TBHD from dry animals, and $22.8 \%$ when animals were wet (Fig. 4).

To determine TBHD underwater, we applied the HF reading from each sensor to its corresponding body surface area (per Fig. 4), and assumed that the proportion of surface area explained by each sensor also represented HF on the animal's opposite side. For seals in air, measurements were prorated to exclude the surface area of
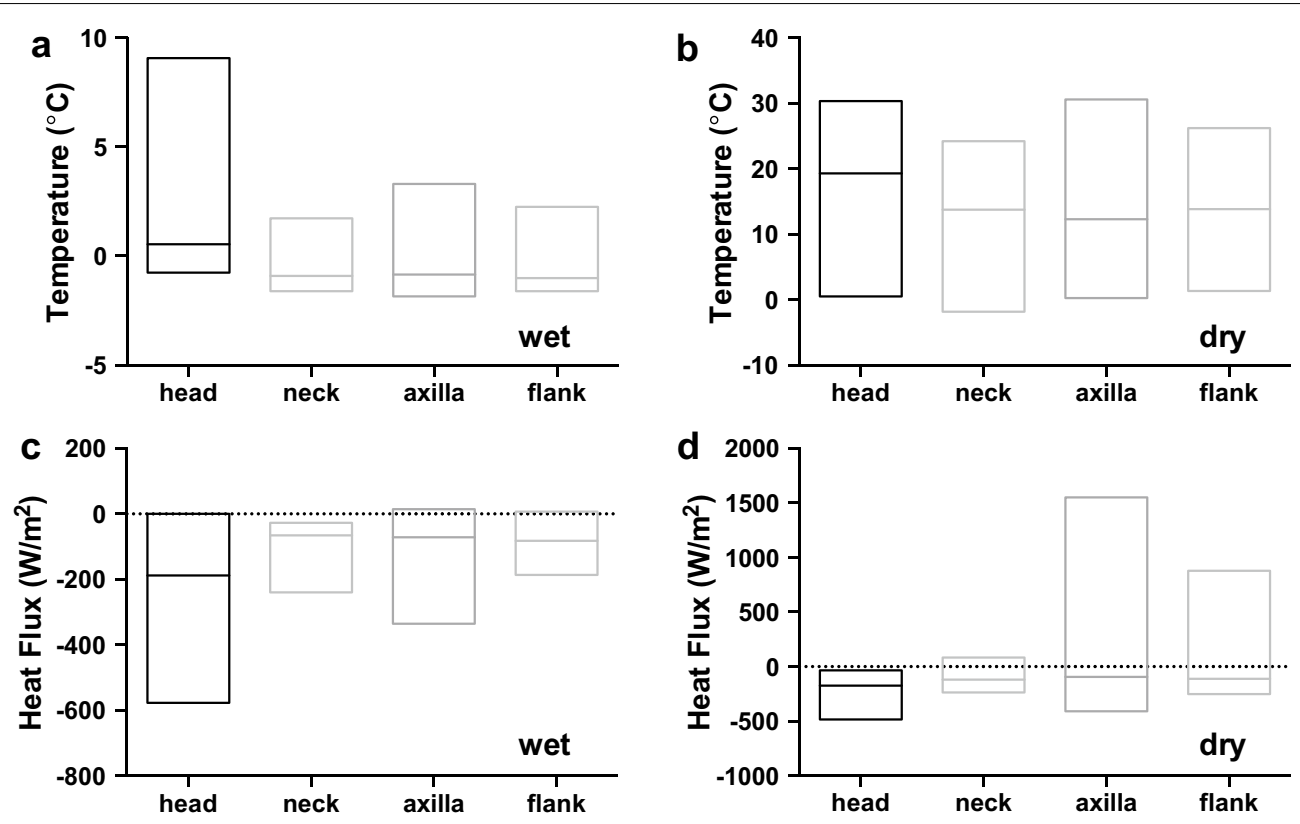

Fig. 3 Temperature and heat flux patterns across four sensor sites. Mean and range of surface temperature and heat flux data collected over the free-ranging period are presented for wet seals $(\mathbf{a}, \mathbf{c})$ and from dry animals hauled-out longer than $6 \mathrm{~h}(\mathbf{b}$, $\mathbf{d})$, which were assumed to be dry and postabsorptive 


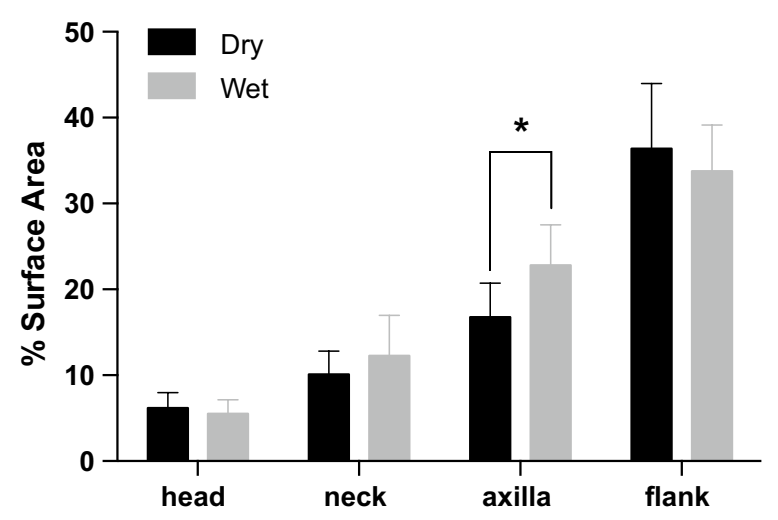

Fig. 4 Proportion of surface area assigned to each heat flux sensor. Using infrared images, we determined the contiguous surface area that bore the same heat signature (surface temperature range) as focal measurements from each sensor location in dry resting $(n=38)$ and wet, recently emerged $(n=14)$ seals

each individual $(32.2 \pm 0.01 \%$ on average $)$ in contact with the ice.

To more accurately model TBHD during haul-out, a predictive equation describing conductive heat loss to the ice was estimated opportunistically from our dataset. By identifying stable periods in the HF data of dry resting seals when sway approached $-1 \mathrm{~g}$, we isolated timepoints when seals were laying flat on their side with axilla and flank sensors pressed between their skin and the ice. Measured conductance in these instances ranged from -1.6 to $-164.9 \mathrm{~W} / \mathrm{m}^{2}$, with a mean of $-67.2 \pm 24.0 \mathrm{~W} /$ $\mathrm{m}^{2}$. There were no differences $(p>0.05)$ between life history groups in heat lost $\left(\mathrm{W} / \mathrm{m}^{2}\right)$ directly to the ice at either the axilla or flank sensor, nor were there significant differences between sensor locations.

We next examined the predictive value of animal morphometrics and environmental variables in determining heat loss to the ice during haul-out using these data. Best-fit LME models indicated that the physical characteristics of individual seals best correlated with heat loss to the ice were average blubber depth, surface area: mass ratio and body volume (LRT $=19.2, p<0.001$; Fig. 5ac). Although air temperature was also related to this $\mathrm{HF}$ (Fig. 5d), this variable was not retained in the best-fit model when physical and environmental characteristics were considered together. Conductive heat loss to the ice during haul-out was best described by:

$$
\begin{aligned}
& \text { Heat flux }\left(\mathrm{W} / \mathrm{m}^{2}\right)=106+9.1 \times \text { blubber } \\
& -0.22 \times \text { volume }-1.46 \times \mathrm{SA}: \text { mass }
\end{aligned}
$$

with average blubber depth in $\mathrm{cm}$, body volume in $\mathrm{L}$ and surface area: mass ratio in $\mathrm{cm}^{2} / \mathrm{kg}$.

\section{Calculating thermoregulation}

To demonstrate how heat dissipation from obligatory thermoregulation $\left(H_{\mathrm{TR}}\right)$ could be identified from these data, we derived Eq. 1 for Weddell seals in air and water. In air, we discount heat costs of locomotion from TBHD, and focused on animals hauled out more than $6 \mathrm{~h}$ to eliminate a potential contribution of HIF [30]. $\mathrm{H}_{\mathrm{TR}}$ was therefore calculated by:

$$
H_{\mathrm{TR}}=\mathrm{TBHD}-H_{\mathrm{BM}}
$$

where $H_{\mathrm{BM}}$ in $\mathrm{W}$ is a mass-derived value based on empirical data collected for resting Weddell seals in air [30] of $4.07 \mathrm{mLO}_{2} / \mathrm{kg} / \mathrm{min}$ (equivalent to $1.35 \mathrm{~W} / \mathrm{kg}$ assuming $\mathrm{RER}=0.77$ ). For all seals in this dataset, the grand mean for $H_{\mathrm{TR}}$ in air was $-23.3 \pm 220 \mathrm{~W}$.

In water, we must eliminate activity and HIF to apply Eq. 3 to calculate $H_{\mathrm{TR}}$. Stomach temperature can be used to identify diving periods before first prey capture [40, 41], which will not contain HIF costs. For initial method development, we analyzed all in-water data together (including surface and dive periods, regardless of potential feeding). We used acceleration (ODBA) to represent activity. TBHD is generally highest at low acceleration (Fig. 6a), likely corresponding to time at or near the water surface. These data cannot reliably be used to estimate activity-free TBHD for HF models as it is not possible to separate additional heat loss due to heat dumping or perfusion changes to the skin on surfacing. Instead, TBHD was estimated at zero swim speed and water flow from the intercept of TBHD regressed against ODBA $>0.5 \mathrm{~g}$ (Fig. 6b). To approximate the intercept representing a minimum boundary line of the plot rather than a leastsquares regression, we analyzed these data with quantile regression, and identified the TBHD intercept from the $75 \%$ quantile (Fig. 6b).

We again derived $H_{\mathrm{BM}}$ from Weddell seals resting in water $\left(3.58 \mathrm{mLO}_{2} / \mathrm{kg} / \mathrm{min}\right.$, equivalent to $\left.1.19 \mathrm{~W} / \mathrm{kg}\right)$ and diving $\left(2.47 \mathrm{mLO}_{2} / \mathrm{kg} / \mathrm{min}\right.$, equivalent to $\left.0.8 \mathrm{~W} / \mathrm{kg}\right)$, based on previously published experimental data [30]. For all seals in this dataset, a general estimate for $H_{\mathrm{TR}}$ in water (including surface and dive periods and without discounting HIF) ranged from $+77.6 \pm 183 \mathrm{~W}$ when $H_{\mathrm{BM}}$ for surface resting was used, to $-7.7 \pm 164 \mathrm{~W}$ using diving $H_{\mathrm{BM}}$.

\section{Field applications: correlations between individual sensors and TBHD}

To consider how much additional information is gained by using all four sensors, we evaluated the independence of the four datasets. The data was best contained in two principal components (PC; Table 1), which explained $41 \%$ (PC1) and $26 \%$ (PC2) of total HF variance. PC1 was 

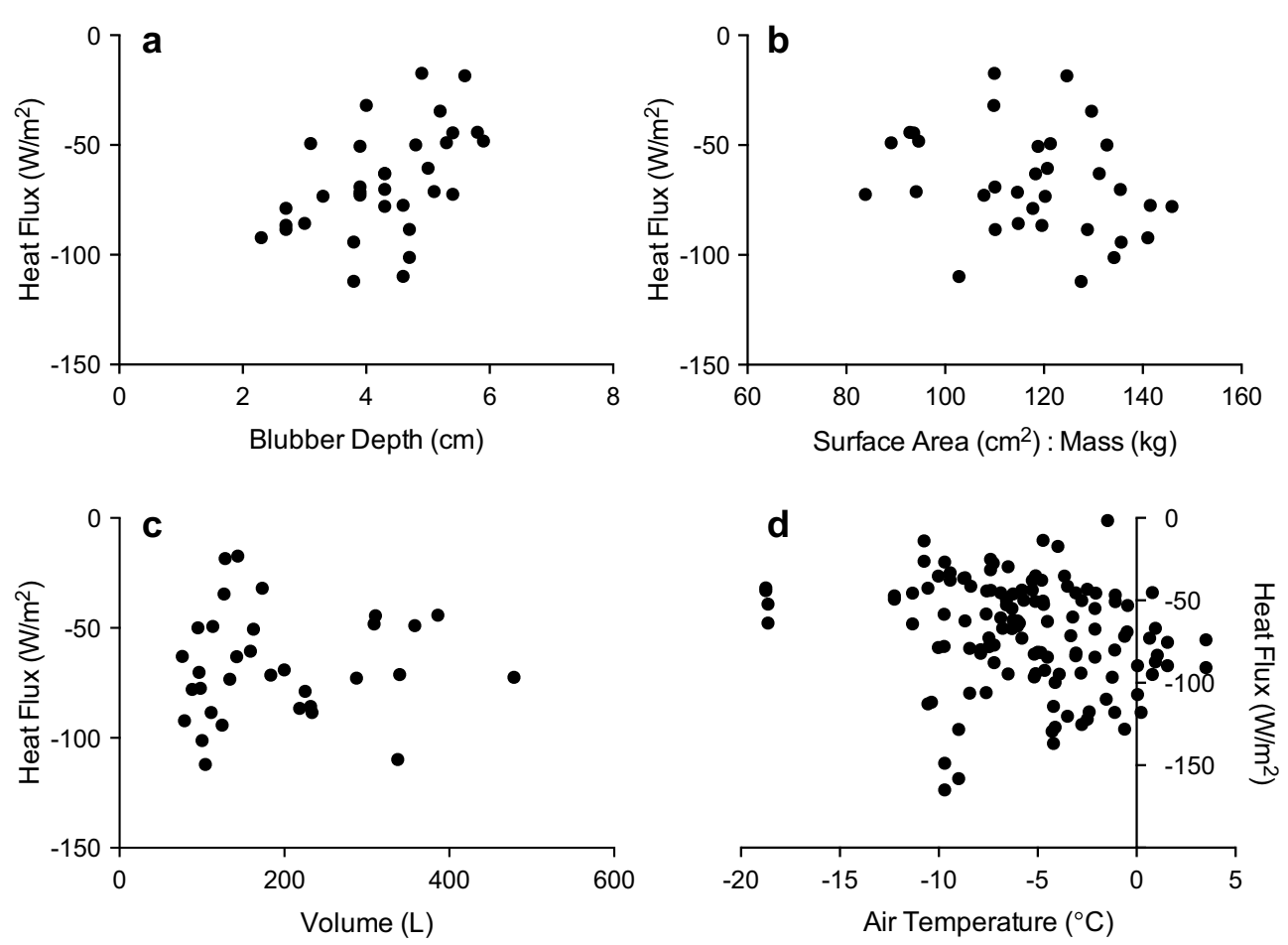

Fig. 5 Physical and environment correlates of heat dissipation directly to the ice during haul-out. Heat transfer was best predicted by blubber depth (a), surface area: mass ratio $(\mathbf{b})$ and body volume $(\mathbf{c})$ in Weddell seals. Air temperature $(\mathbf{d})$ also correlated with heat flux $\left(F_{1,91}=5.3, p=0.02\right)$, but was not retained in the best-fit model

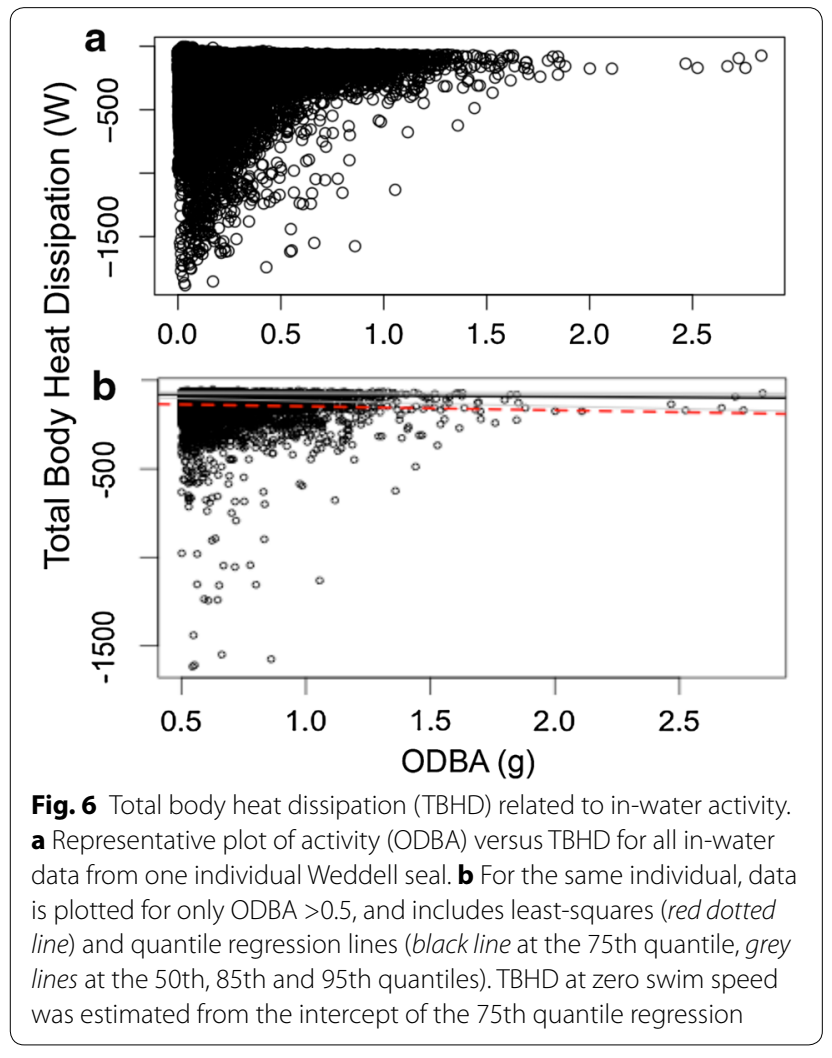

Table 1 Loading and communality scores $\left(h^{2}\right)$ for two principal components $(\mathrm{PC})$ describing variance across heat flux four sensor sites

\begin{tabular}{llll}
\hline Sensor & \multicolumn{2}{l}{ Loading scores } & $\boldsymbol{h}^{\mathbf{2}}$ \\
\cline { 2 - 3 } & PC1 & \\
\hline Head & 0.58 & 0.28 & 0.42 \\
Neck & 0.85 & 0.00 & 0.72 \\
Axilla & 0.08 & 0.97 & 0.96 \\
Flank & 0.76 & 0.04 & 0.57 \\
Proportion explained & $61 \%$ & $39 \%$ & \\
Eigenvalues & 1.74 & 0.92 & \\
\hline
\end{tabular}

Principal components analysis was performed with varimax orthogonal rotation. Sensor sites with loading scores $>0.40$ within a principal component were considered highly associated with that component and are indicated in italics

best correlated to head, neck and flank HF, whereas PC2 was highly correlated with axilla HF (Table 1).

We also examined correlations between individual HF measurements and calculated TBHD with LME models. Not surprisingly, a full model $\left(\mathrm{TBHD} \sim \mathrm{HF}_{\text {head }}+\mathrm{HF}_{\text {neck }}+\mathrm{HF}_{\text {axilla }}+\mathrm{HF}_{\text {flank }}\right)$ best explained calculated TBHD in both environments (Table $2 ; p<0.0001$ ). AIC model selection for only models with single-sensor inputs indicated that the flank 
Table 2 Summary LME model outputs predicting TBHD in wet and dry conditions

\begin{tabular}{|c|c|c|c|c|}
\hline Model & State & $k$ & $\Delta \mathrm{AIC}$ & L-ratio \\
\hline $\begin{array}{c}\mathrm{TBHD} \sim \mathrm{HF}_{\text {head }}+\mathrm{HF}_{\text {neck }} \\
+\mathrm{HF}_{\text {axilla }}+\mathrm{HF}_{\text {flank }}\end{array}$ & Wet & 4 & 0 & $9,654,101$ \\
\hline $\mathrm{TBHD} \sim \mathrm{HF}_{\text {flank }}$ & Wet & 1 & $5,885,893$ & $3,768,202$ \\
\hline $\mathrm{TBHD} \sim \mathrm{HF}_{\text {axilla }}$ & Wet & 1 & $7,591,208$ & $2,062,887$ \\
\hline $\mathrm{TBHD} \sim \mathrm{HF}_{\text {neck }}$ & Wet & 1 & $8,518,031$ & $1,136,064$ \\
\hline $\mathrm{TBHD} \sim \mathrm{HF}_{\text {head }}$ & Wet & 1 & $9,411,749$ & $242,346.1$ \\
\hline Null model & Wet & 0 & $9,654,093$ & - \\
\hline $\begin{array}{c}\mathrm{TBHD} \sim \mathrm{HF}_{\text {head }}+\mathrm{HF}_{\text {neck }} \\
+\mathrm{HF}_{\text {axilla }}+\mathrm{HF}_{\text {flank }}\end{array}$ & Dry & 4 & 0 & $6,922,081$ \\
\hline $\mathrm{TBHD} \sim \mathrm{HF}_{\text {axilla }}$ & Dry & 1 & $4,132,645$ & $2,789,429$ \\
\hline $\mathrm{TBHD} \sim \mathrm{HF}_{\text {flank }}$ & Dry & 1 & $5,942,993$ & $979,081.3$ \\
\hline $\mathrm{TBHD} \sim \mathrm{HF}_{\text {neck }}$ & Dry & 1 & $6,338,992$ & $583,082.3$ \\
\hline $\mathrm{TBHD} \sim \mathrm{HF}_{\text {head }}$ & Dry & 1 & $6,625,552$ & $296,522.6$ \\
\hline Null model & Dry & 0 & $6,922,072$ & - \\
\hline
\end{tabular}

Models are fitted separately for the 'wet' and 'dry' subsets of TBHD data. AIC for single-variable and null models are presented relative to the full model (4 sensor inputs). Log-likelihood ratios ( $L$-ratios) are relative to the Null models and indicate improved fit in all cases $(p<0.0001)$

sensor best explains TBHD with in water, whereas AIC was lowest in air for the axilla model (Table 2). In dry seals ( $>6 \mathrm{~h}$ after haul-out), linear regressions with individual HF sensor channels also demonstrated that axilla explained only slightly less TBHD variation than the full model $\left(r^{2}=0.65\right.$ versus $r^{2}=0.78$ for multiple regression with all four sites). By comparison, head $\left(r^{2}=0.07\right)$, neck $\left(r^{2}=0.10\right)$ and flank $\left(r^{2}=0.15\right)$ alone were less reflective of TBHD. In water by contrast, even the most strongly associated location (flank, $r^{2}=0.55$ ) explained considerably less TBHD variance than the full model $\left(r^{2}=0.90\right.$; head $r^{2}=0.14$, neck $r^{2}=0.33$, axilla $r^{2}=0.51$ ).

\section{Discussion}

This study outlines a method for deploying HF telemetry on a free-ranging marine animal, and for deriving elements of a HF model from the resulting data. With additional analyses incorporating the behavior and physiology that were logged alongside skin surface HF, these data will ultimately provide insight into the thermoregulatory physiology of Weddell seals and other ice-obligate endotherms. Although several layers of calculations are required, and sufficient information about the model system is necessary to validate assumptions, it is possible to generate empirical thermoregulation data that could subsequently be used to frame questions about the impacts of changing ice cover on ice-obligate species. We can also use this dataset to demonstrate how, and under what conditions these inferences are possible, and to identify challenges in using the method.
Our data are generally comparable to previously published pilot measurements on free-ranging Weddell seals [20], yet offer several improvements. For two adult seals in water, Willis and Horning [20] observed point measurements of heat loss to the environment ranging $574.6-1866.2 \mathrm{~W} / \mathrm{m}^{2}$ in two individuals. For the same population of seals, we observed in-water HF of adult females to range from +25 to $-3805 \mathrm{~W} / \mathrm{m}^{2}$. The wider HF range reported here is presumably due to a larger sample size, as well as slightly different sensor placement. Willis and Horning [20] measured HF at four locations along the body trunk from shoulder to hip, but not from head (where we consistently recorded the highest heat loss). Further, we used initial IRT data to determine that the consistently coldest point on the animal was the neck (Fig. 3), which was also not evaluated in the previous study. The HF sensors used in both studies appear similar; however, the current Concept Engineering sensors were solid discs, delivering more consistent performance across a range of depth and pressure than the previous hollow sensors. Further, we have refined our measurements with a greatly simplified attachment system to achieve a correction factor of $1.25 \times$ for the attachment, versus $3.42 \times$ reported previously. This indicates that our attachment resulted in a far lower impact on the actual measurement [42]. While the core of our dataset is skin surface HF measurements, essentially similar to Willis and Horning [20], this study includes several conceptual steps forward. By combining IRT data with surface area/ volumetric modeling for each individual, we were able to develop a system for extrapolating point measurements into a whole-body metric, and for determining heat lost directly to the ice during haul-out. We additionally collected and analyzed data from varied size and condition animals over a wider seasonal range, and included measurements in air and water to provide a broader picture of Weddell seal thermoregulation.

\section{Regional heat flux}

In order to collect data in air and water from free-ranging animals, whole-body metrics of heat loss are necessarily extrapolated from point measurements. Measurement locations must either be representative of total body heat flux, or encompass whole-body thermal variability when several locations are combined. Previous studies have identified high obligate heat loss associated with sensory systems (head, eyes and vibrissae) in pinnipeds [43-47]. IRT identified these regions as potential "hot spots" in Weddell seals, therefore head was included as a sensor site. While the head did demonstrate the highest skin temperatures and HF in this dataset, particularly in water, temperature dynamics were also extremely 
variable, occasionally approaching ambient during diving, with HF falling near zero (Fig. 3).

Significant heat loss is also possible from the flippers [48-52], which we did not measure. However, heat dissipation from phocid flippers is likely maximized only in warm ambient conditions, whereas they demonstrate limited thermal emissivity in cold $[49,53,54]$. Our sensor attachment system effectively reduces impacts on the measurement, but provides only a temporary attachment that may last several days or weeks, and is likely to detach from highly mobile areas. We, therefore, excluded the flippers for HF measurements partly due to logistics, and partly because it is reasonable to speculate that Weddell seals do not disproportionately rely on their flippers for thermoregulation. The previous analyses of IRT in dry resting seals did not demonstrate surface temperature distinctions between fore- and hindflippers, nor differences between flippers and other body regions [13]. Further, a consistent distribution of arteriovenous anastomoses across the entire skin surface of Weddell seals also suggests that the flippers do not have an enhanced role in thermoregulation relative to the rest of the body [55].

The thermal signatures associated with axilla and flank sensors explained the largest portions of body surface area. Axilla was the only sensor associated with a differently sized thermal signature between air and water. The thoracic region has already been demonstrated as important for active thermoregulation in freely diving Antarctic fur seals [18], and our observation of a larger axilla thermal signature in recently emerged animals extends this finding to Weddell seals. Lateral axilla also displayed the highest skin temperatures and heat loss in water of all sites excepting head (Fig. 3), despite its association with the greatest regional blubber depth measured in this species [34]. Together, this indicates that axilla may be an important site for obligate heat loss, perhaps reflecting its proximity to the body core. The flank sensor was, on the other hand, placed to capture activity-specific heat signatures underwater, according to a transient "hot spot" observed in IRT images of recently emerged seals, indicative of locomotory heat production and dissipation.

\section{Field application: sensor sites}

It is important to consider the challenges and limitations of this method for field data collection. We used four HF sensors, intended to capture the range and variability of thermal patterns across the body. Therefore, we determined the number of independent variables needed to describe HF variance among the four sensors as a way to consider the impact of reducing sensor number. Inputs from all four sensors were best described by two principal components. While head, neck and flank were highly associated with PC1, while axilla was highly associated with PC2 (Table 1), suggesting that data from only one sensor is not sufficient to capture the HF variability observed at our four sensor sites under all conditions. Importantly, regressions describing single-sensor HF versus calculated TBHD differed between air and water. Axilla HF was strongly related to TBHD in hauledout seals $\left(r^{2}=0.65\right)$, with limited improvement provided by other sensors $\left(r^{2}=0.78\right.$ with all four inputs). This indicates that axilla alone is the most useful, of the sites selected here, for understanding Weddell seal thermoregulation in air. In water, however, flank $\left(r^{2}=0.55\right)$ and axilla $\left(r^{2}=0.51\right)$ explained similar variance in calculated TBHD, and neither approached the regression achieved with all four sensors $\left(r^{2}=0.90\right)$. This indicates that a single-sensor measurement in water will significantly reduce the information collected about wholebody heat loss. Taken together, our analysis suggests that if a reduced number of sensors must be used to estimate heat loss in air and water, the axilla and flank locations are most descriptive of TBHD. Only a limited proportion of head HF variance $\left(h^{2}=0.42\right)$ was explained with two principal components, and associations between head and TBHD were low, possibly due to its small surface area applied to calculate TBHD. The limited contribution of heat loss from the head implies the lack of a wholebody impact from potentially high obligate heat loss in sensory regions. Yet, it is also possible that the dynamics of heat loss from the head are important under specific conditions, which are not likely captured by this method.

\section{Field applications: estimating thermoregulatory costs}

Using published estimates of basal metabolic rates in air, at the water surface, and during diving, as well as respiratory exchange ratios for this species [30], we generated $H_{\mathrm{TR}}$ (obligate heat costs of thermoregulation) in air and water for our dataset. Our initial estimates of $H_{\mathrm{TR}}$ are not intended to be benchmarks for the species, but rather to provide example calculations for the method. Subsequent efforts are needed to determine the effects of physical (morphometric) and environmental variables on thermoregulation, as well as the relationship between feeding and underwater activity on heat loss. The possibility that Weddell seals do not maintain stable core body temperature during diving must also be considered, in light of conflicting observations of regional blood temperature dynamics in deep-diving seals $[56,57]$.

These initial results do, however, highlight several features of TBHD in Weddell seals that should be considered in subsequent investigations in this or other species. (1) Positive HF and TBHD measured in air indicate that radiative heat gain may have a significant impact on thermoregulation during haul-out. (2) $H_{\mathrm{TR}}$ costs 
appear minimal under some conditions, therefore accurate species- and condition-specific estimates of resting metabolic rates in captive of controlled settings will be valuable for accurate parsing of TBHD. (3) HF models as they are applied here are valid only under steady-state conditions. Companion behavioral or physiological data are therefore important to provide context to HF measurements. For instance, in-water measurements should be refined not only by exercise level but by depth, to separate activities.

\section{Summary}

Thermoregulatory physiology provides an important context for understanding the adaptation of species to polar habitats, and is likely a trait that will influence the unique responses of species to habitat disruption. Further efforts are needed, specifically for ice-obligate pinnipeds, to understand basic thermoregulatory differences between air and water. Altered time in water is the predicted outcome of changes in sea ice dynamics, by affecting prey distributions and thus foraging time, as well as restricting access to haul-out substrates at times critical for ontogeny [15] or molt [58]. HF biologging provides timely empirical data that can be applied to parameterize species-specific energetics models, and to identify life history or body condition stages with different thermoregulatory thresholds, that confer susceptibility to altered habitats.

\section{Additional file}

Additional file 1. Data processing and analysis schematic for deriving total body heat dissipation (TBHD) from skin surface heat flux (HF) sensors, as applied from free-ranging Weddell seals. Figure, table, and equation references refer to the presentation or analysis of relevant data in the manuscript. Raw HF data was manually curated to crop regions with obviously damaged sensors then filtered to improve signal to noise ratio (described in detail in Methods). Photogrammetry wireframes were used to estimate total body surface area, and the surface area of each individual's contact with the ice during haul-out. Heat loss directly to the ice was predicted from empirical data collected with this dataset (Equation 2). To derive TBHD, HF at each sensor site was applied over the contiguous proportion of body surface area estimated to match the infrared surface temperature profiles (histograms and range of values) of focal site measurements for dry versus wet seals.

\section{Authors' contributions}

AH conceived of the concept, conducted the field study, performed the analyses, and drafted the manuscript. MH conceived of the concept, designed the integrated telemetry package, conducted the field study and participated in the analyses. JM conceived of the concept, conducted the field study, collected and processed the infrared images, and revised the paper. All authors read and approved the final manuscript.

\section{Author details}

${ }^{1}$ Department Anesthesia, Critical Care and Pain Medicine, Massachusetts General Hospital, Harvard Medical School, Boston, MA 02114, USA. ${ }^{2}$ Alaska SeaLife Center, Seward, AK 99664, USA. ${ }^{3}$ Department Fisheries and Wildlife, Oregon
State University, Newport, OR, USA. ${ }^{4}$ School of Fisheries and Ocean Sciences, University of Alaska Fairbanks, Fairbanks, AK, USA.

\section{Acknowledgements}

We gratefully acknowledge the field efforts of R. Berngartt, R. Hill, H. Kaiser, M. Monnin and J. Skinner. M. Monnin collected the photogrammetry data and constructed the wireframes for estimating animal surface area and volume. J. Skinner provided data analyses and statistics consulting and assistance. We also thank B. Volpov for helpful discussion about data processing scripts and C. Shuert for editorial comments on the manuscript. Logistical support for this project in Antarctica was provided by the US National Science Foundation through the U.S. Antarctic Program. (Award \#1043779).

\section{Competing interests}

The authors declare that they have no competing interests.

Received: 30 January 2015 Accepted: 11 September 2015 Published online: 16 October 2015

\section{References}

1. Stammerjohn S, Massom R, Rind D, Martinson D. Regions of rapid sea ice change: An inter-hemispheric seasonal comparison. Geophys Res Lett. 2012;39(6):L06501. doi:10.1029/2012GL050874.

2. Stocker TF, Qin D, Plattner G-K, Alexander LV, Allen SK, Bindoff NL et al. Technical summary. In: Stocker TF, Qin D, Plattner G-K, Tignor M, Allen SK, Boschung J, Nauels A, Xia Y, Bex V, Midgley PM, editors. Climate change 2013: the physical science basis. Contribution of Working Group I to the Fifth Assessment Report of the Intergovernmental Panel on Climate Change. Cambridge and New York: Cambridge University Press; 2013.

3. Tareghian R, Rasmussen P. Analysis of Arctic and Antarctic sea ice extent using quantile regression. Int J Climatol. 2013;33(5):1079-86. doi:10.1002/ joc.3491.

4. Ducklow HW, Baker K, Martinson DG, Quetin LB, Ross RM, Smith RC, et al. Marine pelagic ecosystems: the West Antarctic Peninsula. Phil Trans R Soc B. 2007;362(1477):67-94.

5. Pritchard HD, Ligtenberg SRM, Fricker HA, Vaughan DG, van den Broeke MR, Padman L. Antarctic ice-sheet loss driven by basal melting of ice shelves. Nature. 2012;484(7395):502-5.

6. Comiso JC, Kwok R, Martin S, Gordon AL. Variability and trends in sea ice extent and ice production in the Ross Sea. J Geophys Res Oceans. 2011;116(C4):C04021. doi:10.1029/2010JC006391.

7. Boily P. Theoretical heat flux in water and habitat selection of phocid seals and beluga whales during the annual molt. J Theor Biol. 1995;172(3):23544. doi:10.1006/jtbi.1995.0020.

8. Gallivan GJ, Ronald K. Apparent specific dynamic action in the harp seal (Phoca groenlandica). Comp Biochem Physiol A. 1981;69(3):579-81. doi:10.1016/0300-9629(81)93024-3.

9. Gmuca NV, Pearson LE, Burns JM, Liwanag HEM. The fat and the furriest: morphological changes in harp seal fur with ontogeny. Physiol Biochem Zool. doi:10.1086/680080. (In press)

10. Hokkanen JE. Temperature regulation of marine mammals. J Theor Biol. 1990;145(4):465-85.

11. Irving L, Hart JS. The metabolism and insulatino of seals as bare-skinned mammals in cold water. Can J Zool. 1957;35(4):497-511. doi:10.1139/ z57-041.

12. Kvadsheim PH, Folkow LP, Blix AS. Inhibition of shivering in hypothermic seals during diving. Am J Physiol Regul Integr Comp Physiol. 2005;289(2):R326-31. doi:10.1152/ajpregu.00708.2004.

13. Mellish J-A, Hindle A, Skinner J, Horning M. Heat loss in air of an Antarctic marine mammal, the Weddell seal. J Comp Physiol B. 2015;185:143-52. doi:10.1007/s00360-014-0868-2.

14. Noren SR, Pearson LE, Davis J, Trumble SJ, Kanatous SB. Different thermoregulatory strategies in nearly weaned pup, yearling, and adult Weddell seals (Leptonychotes weddelli). Physiol Biochem Zool. 2008;81(6):86879. doi:10.1086/588489.

15. Pearson LE, Liwanag HEM, Hammill MO, Burns JM. To each its own: Thermoregulatory strategy varies among neonatal polar 
phocids. Comp Biochem Physiol A. 2014;178:59-67. doi:10.1016/j. cbpa.2014.08.006.

16. Pearson LE, Liwanag HEM, Hammill MO, Burns JM. Shifts in thermoregulatory strategy during ontogeny in harp seals (Pagophilus groenlandicus). J Therm Biol. 2014;44:93-102. doi:10.1016/j.jtherbio.2014.02.001.

17. Ryg M, Smith TG, Øritsland NA. Thermal significance of the topographical distribution of blubber in ringed seals (Phoca hispida). Can J Fish Aquat Sci. 1988;45(6):985-92. doi:10.1139/f88-121.

18. Boyd IL. Skin temperatures during free-ranging swimming and diving in antarctic fur seals. J Exp Biol. 2000;203(12):1907-14.

19. Westgate AJ, McLellan WA, Wells RS, Scott MD, Meagher EM, Pabst DA. A new device to remotely measure heat flux and skin temperature from free-swimming dolphins. J Exp Mar Biol Ecol. 2007;346(1-2):45-59. doi:10.1016/j.jembe.2007.02.014.

20. Willis $K$, Horning M. A novel approach to measuring heat flux in swimming animals. J Exp Mar Biol Ecol. 2005;315(2):147-62. doi:10.1016/j. jembe.2004.09.019.

21. Nadel ER. Energy exchanges in water. Undersea Biomed Res. 1984;11(2):149-58.

22. Lovvorn JR. Thermal substitution and aerobic efficiency: measuring and predicting effects of heat balance on endotherm diving energetics. Phil Trans Royal Soc B. 2007;362(1487):2079-93. doi:10.1098/ rstb.2007.2110.

23. Campbell KL, McIntyre IW, MacArthur RA. Postprandial heat increment does not substitute for active thermogenesis in cold-challenged starnosed moles (Condylura cristata). J Exp Biol. 2000;203(2):301-10.

24. Rosen DAS, Trites AW. No evidence for bioenergetic interaction between digestion and thermoregulation in Steller sea lions Eumetopias jubatus. Physiol Biochem Zool. 2003;76(6):899-906. doi:10.1086/378140.

25. MacArthur RA, Campbell KL. Heat increment of feeding and its thermoregulatory benefit in the muskrat (Ondatra zibethicus). J Comp Physiol B. 1994;164(2):141-6. doi:10.1007/BF00301656.

26. Costa DP, Kooyman GL. Contribution of specific dynamic action to heat balance and thermoregulation in the sea otter Enhydra lutris. Physiol Zool. 1984:57(2):199-203. doi:10.2307/30163705.

27. Dassis M, Rodríguez DH, leno EN, Denuncio PE, Loureiro J, Davis RW. Resting metabolic rate and heat increment of feeding in juvenile South American fur seals (Arctocephalus australis). Comp Biochem Physiol A. 2014;168:63-8. doi:10.1016/j.cbpa.2013.11.007.

28. Markussen NH, Ryg M, Øritsland NA. The effect of feeding on the metabolic rate in harbour seals (Phoca vitulina). J Comp Physiol B. 1994;164(2):89-93. doi:10.1007/BF00301648.

29. Ponganis PJ, Kooyman GL, Castellini MA. Determinants of the aerobic dive limit of Weddell seals: analysis of diving metabolic rates, postdive end tidal Po2's, and blood and muscle oxygen stores. Physiol Zool. 1993;66(5):732-49. doi:10.2307/30163821.

30. Williams TM, Fuiman LA, Horning M, Davis RW. The cost of foraging by a marine predator, the Weddell seal Leptonychotes weddellii: pricing by the stroke. J Exp Biol. 2004;207(6):973-82. doi:10.1242/jeb.00822.

31. Humphries MM, Careau V. Heat for nothing or activity for free? Evidence and implications of activity-thermoregulatory heat substitution. Integr Comp Biol. 2011;. doi:10.1093/icb/icr059.

32. Costa DP, Williams TM. Marine mammal energetics. In: Reynolds JE, Rommel SA, editors. Biology of marine mammals. Washington, D.C.: Smithsonian Institution Press; 1999. p. 176-217.

33. Mellish JA, Tuomi PA, Hindle AG, Horning M. Chemical immobilization of Weddell seals (Leptonychotes weddellii) by ketamine/ midazolam combination. Vet Anaesth Analg. 2010;37(2):123-31. doi:10.1111/j.1467-2995.2009.00517.x.

34. Mellish J-AE, Hindle AG, Horning M. Health and condition in the adult Weddell seal of McMurdo Sound Antarctica. Zoology. 2011;114(3):17783. doi:10.1016/j.zool.2010.11.007.

35. Hindle A, Rosen D, Trites A. Swimming depth and ocean currents affect transit costs in Steller sea lions Eumetopias jubatus. Aquat Biol. 2010;10(2):139-48. doi:10.3354/ab00279.

36. Shepard EL, Wilson RP, Halsey LG, Quintana F, Gomez Laich A, Gleiss AC, et al. Derivation of body motion via appropriate smoothing of acceleration data. Aquat Biol. 2009;4(3):235-41.
37. Revelle W. psych: Procedures for personality and psychological research. Version 1.4.5. Northwestern University, Evanston. http://CRAN.R-project. org/package=psych. 2014.

38. Koenker R. quantreg: Quantile Regression. R package version 505. http:// CRAN.R-project.org/package=quantreg. 2013

39. Team RDC. R: a language for statistical computing. R Foundation for Statistical Computing. 2013.

40. Ancel A, Horning M, Kooyman GL. Prey ingestion revealed by oesophagus and stomach temperature recordings in cormorants. J Exp Biol. 1997;200(1):149-54.

41. Kuhn CE, Costa DP. Identifying and quantifying prey consumption using stomach temperature change in pinnipeds. J Exp Biol. 2006;209(22):4524-32. doi:10.1242/jeb.02530.

42. Frim J, Ducharme MB. Heat flux transducer measurement error: a simplified view. J Appl Physiol. 1993;74(4):2040-4.

43. Dehnhardt G, Mauck B, Hyvärinen H. Ambient temperature does not affect the tactile sensitivity of mystacial vibrissae in harbour seals. J Exp Biol. 1998;201(22):3023-9.

44. Erdsack N, Dehnhardt G, Witt M, Wree A, Siebert U, Hanke W. Unique fur and skin structure in harbour seals (Phoca vitulina) - thermal insulation, drag reduction, or both? J R Soc Interface. 2015;12:20141206.

45. Mauck B, Eysel U, Dehnhardt G. Selective heating of vibrissal follicles in seals (Phoca vitulina) and dolphins (Sotalia fluviatilis guianensis). J Exp Biol. 2000;203(14):2125-31.

46. McCafferty DJ, Moss S, Bennett K, Pomeroy PP. Factors influencing the radiative surface temperature of grey seal (Halichoerus grypus) pups during early and late lactation. J Comp Physiol B. 2005;175(6):423-31. doi:10.1007/s00360-005-0004-4.

47. Nienaber J, Thomton J, Horning M, Polasek L, Mellish J-A. Surface temperature patterns in seals and sea lions: a validation of temporal and spatial consistency. J Therm Biol. 2010;35(8):435-40. doi:10.1016/j. jtherbio.2010.09.005.

48. Gallivan GJ, Ronald K. Temperature regulation in freely diving harp seals (Phoca groenlandica). Can J Zool. 1979;57(11):2256-63. doi:10.1139/ z79-293.

49. Hart JS, Irving L, Mackenzie B. The energetics of harbor seals in air and water with special consideration of seasonal changes. Can J Zool. 1959;37(4):447-57. doi:10.1139/259-052.

50. Kvadsheim PH, Gotaas ARL, Folkow LP, Blix AS. An experimental validation of heat loss models for marine mammals. J Theor Biol. 1997;184(1):15-23. doi:10.1006/jtbi.1996.0256.

51. Mauck B, Bilgmann K, Jones DD, Eysel U, Dehnhardt G. Thermal windows on the trunk of hauled-out seals: hot spots for thermoregulatory evaporation? J Exp Biol. 2003;206(10):1727-38. doi:10.1242/jeb.00348.

52. Tarasoff FJ, Fisher HD. Anatomy of the hind flippers of two species of seals with reference to thermoregulation. Can J Zool. 1970;48(4):821-9. doi:10.1139/z70-144.

53. Khamas WA, Smodlaka H, Leach-Robinson J, Palmer L. Skin histology and its role in heat dissipation in three pinniped species. Acta Vet Scand. 2012;54(1):46. doi:10.1186/1751-0147-54-46.

54. Kvadsheim PH, Folkow LP. Blubber and flipper heat transfer in harp seals. Acta Physiol Scand. 1997;161(3):385-95. doi:10.1046/j.1365-201X.1997.00235.x

55. Molyneux G, Bryden M. Arteriovenous anastomoses in the skin of the Weddell Seal, Leptonychotes weddelli. Science. 1975;189(4208):1100-2. doi:10.1126/science.1162361.

56. Hill RD, Schneider RC, Liggins GC, Schuette AH, Elliott RL, Guppy M, et al. Heart rate and body temperature during free diving of Weddell seals. Am J Physiol Regul Integr Comp Physiol. 1987;253(2):R344-51.

57. Meir JU, Ponganis PJ. Blood temperature profiles of diving elephant seals. Physiol Biochem Zool. 2010;83(3):531-40. doi:10.1086/651070.

58. Paterson W, Sparling CE, Thompson D, Pomeroy PP, Currie Jl, McCafferty DJ. Seals like it hot: Changes in surface temperature of harbour seals (Phoca vitulina) from late pregnancy to moult. J Therm Biol. 2012;37(6):454-61. doi:10.1016/j.jtherbio.2012.03.004. 